
\title{
$\begin{array}{ll}\text { Research Square } & \text { Preprints are preliminary reports that have not undergone peer review. } \\ \text { They should not be considered conclusive, used to inform clinical practice, } \\ \text { or referenced by the media as validated information. }\end{array}$
}

\section{Indicators of the molecular pathogenesis of virulent Newcastle Disease Virus in chickens revealed by transcriptomic profiling of spleen}

Mohammad Rabiei ( $\sim$ mohammad.rabiei@adelaide.edu.au )

School of Animal and Veterinary Sciences, The University of Adelaide, Adelaide, Australia

Wai Yee Low

The Davies Research Centre, School of Animal and Veterinary Sciences, The University of Adelaide, Adelaide, Australia

\section{Milton McAllister}

School of Animal and Veterinary Sciences, The University of Adelaide, Adelaide, Australia

\section{Yan Ren}

The Davies Research Centre, School of Animal and Veterinary Sciences, The University of Adelaide, Adelaide, Australia

\section{Mohamad Cahyono}

Indonesian Research Centre for Veterinary Science, Bogor, West Java, Indonesia

\section{Phuong Doan}

School of Animal and Veterinary Sciences, The University of Adelaide, Adelaide, Australia Indi Dharmayanti

Indonesian Research Centre for Veterinary Science, Bogor, West Java, Indonesia

\section{Eleonora Grande}

School of Animal and Veterinary Sciences, The University of Adelaide, Adelaide, Australia

\section{Farhid Hemmatzadeh}

School of Animal and Veterinary Sciences, The University of Adelaide, Adelaide, Australia

\section{Research Article}

Keywords: Newcastle disease virus, Gene expression profile, Chicken spleen, Apoptosis, Necroptosis, Autophagy

Posted Date: December 17th, 2020

DOI: https://doi.org/10.21203/rs.3.rs-123311/v1

License: (c) (1) This work is licensed under a Creative Commons Attribution 4.0 International License. Read Full License 
Version of Record: A version of this preprint was published at Scientific Reports on September 2nd, 2021. See the published version at https://doi.org/10.1038/s41598-021-96929-w. 


\section{Abstract}

Newcastle disease virus (NDV) has caused significant outbreaks in South-East Asia, particularly in Indonesia in recent years. Recently emerged genotype VII NDVs (NDV-GVII) have shifted their tropism from gastrointestinal/respiratory tropism to a lymphotropic virus, invading lymphoid organs including spleen and bursa of Fabricius to cause profound lymphoid depletion. In this study, we aimed to identify candidate genes and biological pathways that contribute to the disease caused by this neurotropic velogenic NDV-GVII. A transcriptomic analysis based on RNA-Seq of spleen was performed in chickens challenged with NDV-GVII and a control group. In total, 6361 genes were differentially expressed that included 3506 up-regulated genes and 2855 down-regulated genes. Real-Time PCR of ten selected genes validated the RNA-Seq results as the correlation between them is 0.98 . Functional and network analysis of DEGs showed altered regulation of EIF2 signalling, mTOR signalling, proliferation of lymphatic system cells, signalling by Rho family GTPases and synaptogenesis signalling in spleen. We have also identified modified expression of IFIT5, PI3K, AGT and PLP1 genes in NDV-GVII infected chickens. Our findings in activation of autophagy-mediated cell death, lymphotropic and synaptogenesis signalling pathways provide new insights into the molecular pathogenesis of this newly emerged NDV-GVII.

\section{Introduction}

Newcastle disease virus (NDV) has a worldwide distribution. The NDV causes infection in many different avian species, and it can be considered a permanent threat to all poultry industries and other fields of aviculture ${ }^{1}$. NDV is capable of causing devastating infection for over 240 species of birds that can spillover through direct contact between healthy and infected birds ${ }^{2,3}$. The World Organization for Animal Health (the OIE) has ranked Newcastle Disease as a list-A disease with other critical diseases such as Avian Influenza ${ }^{4}$. NDV was first reported in Java, Indonesia in 1926 and then spread to the rest of the world. Various genotypes have been responsible for different ND panzootics ${ }^{5}$. Most recent ND outbreaks in Southeast Asia are mainly caused by highly virulent NDV-GVII leading to $70-80 \%$ mortality in commercial chickens, including vaccinated flocks ${ }^{6,7}$. While genotype VII NDVs includes a wide variety of sub-genotypes, the fourth and the fifth ND panzootic in Africa, Europe, Middle East and Asia were caused by genotype VII.1.1 (b, d, e, j, I) and VII.2 (a, h, i, k), respectively ${ }^{7-9}$.

NDV is a member of the genus avian orthoavulavirus 1 within a new subfamily Avulavirinae of the family Paramyxoviridae ${ }^{8}$. NDV has a negative-sense single-stranded, and non-segmented RNA genome that encodes six major structural protein genes in the order $3^{\prime}-\mathrm{NP}-\mathrm{P}-\mathrm{M}-\mathrm{F}-\mathrm{HN}-\mathrm{L}-5^{\prime}{ }^{10}$. According to the clinical signs in infected chickens, different strains of NDV have been separated into five groups ${ }^{11}$ : (I) Viscerotropic velogenic strains causing acute lethal infections, usually causing haemorrhagic lesions in the intestines; (II) Neurotropic velogenic strains causing high mortality with neurological disease followed by respiratory symptoms without gut lesions; (III) Mesogenic strains causing low mortality with respiratory and neurological signs; (IV) Lentogenic strains causing mild infections of the respiratory tract without any lesions in the intestinal tract; and (V) Avirulent strains that replicate in the intestine with no 
clinical signs. Avirulent strains are often used as live vaccines ${ }^{7}$. Phylogenetic analysis of the fusion protein gene of NDVs indicates that circulating strains in Indonesia are belonging to genotype VII. 2 with a mean death time (MDT) from 60 to 67 hour as their pathogenicity index ${ }^{10,12,13}$. These findings also indicate that these circulating strains are clinically categorised as neurotropic velogenic. In this study, we have used one of these genotype VII NDV strains in our challenge experiment in order to analyse pathogenesis of this newly emerged NDV ${ }^{12}$. The amino acid composition of cleavage site of the fusion protein and its susceptibility to host trypsin-like proteases plays a big role in pathogenicity, spread of infection, and tissue tropism of NDVs ${ }^{14}$. Mucosal immunity is heavily involved in the host response to ND infection. Trachea, Harderian glands and lung are places for early virus/host contact at points of entry. These tissues are strategic sites to examine host-pathogen interaction and early viral shedding. Several studies investigated the transcriptome of these tissues infected by NDV ${ }^{15-17}$. In order to increase understanding of the immune response to NDV, the gene expression profile of other immune organs should also be considered. The spleen is the primary immune organ in birds and the place of maturation of B cells, antibody synthesises, screening of pathogens in peripheral blood and replication of leukocytes 18. Recent in vivo studies revealed differential regulation of immune response to the lentogenic strain of NDV (LaSota) by transcriptome analysis in the spleen ${ }^{19,20}$. Another in vitro study compared transcript profile of highly virulent Herts/33 strain and nonvirulent LaSota strain in spleen cells ${ }^{21}$. The transcriptomic analysis of infection caused by newly emerged virulent NDV-GVII has not been investigated in previous studies.

Cell death has been divided into three categories: (1) type I cell death or apoptosis; (2) type II cell death or necrosis; (3) type III cell death or autophagy ${ }^{22}$. Apoptosis is critical in both physiological and pathological conditions and is known as a multi-pathway process, which can lead to programmed cell death. Apoptosis is associated with many types of viral infections and, depending on the circumstances, can act to increase or decrease viral production. Apoptosis is a hallmark of cytotoxicity in virus-infected cells with NDV strains that can trigger both extrinsic and intrinsic apoptotic pathways ${ }^{23}$, and numerous in-vitro and in-vivo studies have shown that NDV can trigger the apoptosis process ${ }^{24-27}$. Different studies have shown that infection with the virulent strains of NDV will increase the apoptosis in lymphoid tissue and immune cells ${ }^{24,28-30}$. Severe splenic disruption, massive lymphoid depletion, ulceration of the intestinal epithelium and rapid depletion of the bursa of Fabricius have been described in association with these strains ${ }^{24,28-31}$. Other members of Paramyxoviridae family such as Rinderpest ${ }^{32}$, canine distemper, measles ${ }^{33} 34,35$, and porcine Rubulavirus ${ }^{36}$ similarly targeting the host lymphoid tissues. An important difference between apoptosis and necrosis is that apoptosis does not incite inflammation ${ }^{27}$.

Due to existing the neuropathogenic genetic markers in our NDV isolates ${ }^{10,12,13}$, we were expecting to observe neurological lesions and respiratory symptoms as the classical symptoms of virulent NDV strains. Surprisingly, we have detected almost no NDVs in the central nervous system, while massive lymphoid depletion observed in studied chickens. In this study, we aimed to identify the molecular basis of pathogenesis of newly emerged NDV-GVII using mRNA profiling of spleen tissues in experimentally 
infected chickens. To do that, we have focused on cell death related pathways and functional analysis of genes to reveal their potential roles in massive cellular depletion in spleen lymphoid tissues. To our knowledge, this is the first in vivo study investigating gene expression profile of this neurotropic velogenic strain.

\section{Results}

\section{Detection of virus shed in challenged group.}

To examine effects of virus on experimentally challenged birds, the Ross broiler chickens were inoculated with a genotype VII NDV. Due to the severe sickness caused by the virus in challenged group, experiment terminated by euthanising of all birds at $2 \mathrm{dpi}$ and a cloacal swab has also been taken from all birds including control group. The results of absolute quantification for detection of viral fusion gene in samples by qPCR confirmed that all the birds inoculated with NDV-GVII became infected and shed virus at $2 \mathrm{dpi}$. The mean cycle threshold $(C t)$ value of the challenge group $(16.9, S D=1.22)$ was lower than the control group (41.9 SD=2.92) ( $F=967.4, d f=14, p<0.001)$, which indicated viral shedding in the challenged group while there was no detection of NDV in control group.

\section{Gene Expression Changes Induced by NDV infection}

Sequencing of constructed libraries from RNA samples resulted 400 million of 100-bp paired end reads. Similar percentages of reads from each sample (on average 76\%) were mapped to the GRCg6a reference genome in the Ensembl database and could be counted as a gene feature by the software Feature Count (Table 1). Of the 24,362 annotated genes in the reference genome, 14,664 ( 60\%) genes were considered as expressed after our count per million cut-off criteria. By applying the FDR p-value cut-off of 0.05 and log2 fold change more than 1, our analysis revealed 6361 differentially expressed genes (DEGs). 3,506 genes were upregulated, and 2,855 genes were downregulated DEGs (Supplementary Table S1 and Figure 1). Non-coding RNA transcripts are about $90 \%$ of the eukaryotic genome and do not follow the central dogma for the flow of genetic information in cells. Although several studies aimed to analyse their existence, a significant challenge exists in terms of their molecular functions and mechanisms of action 37. One of the rapidly expanding fields of this class of transcripts is the long non-coding RNA (IncRNA). A considerable number of transcripts (732) of IncRNA has been detected in our analysis, and interestingly, 513 of these transcripts had the highest (LFC is <-3 or $>3$ ) change in expression (Supplementary Table S2). None of the studied genes were included in our analysis due to the lack of a chicken-based biological pathway database for gene expression analysis. 


\begin{tabular}{|l|r|r|l|}
\hline Sample & \multicolumn{1}{|l|}{ Raw count } & \multicolumn{1}{|l|}{ Cleaned count } & Mapping \% \\
\hline Control 1 & $291,052,64$ & $268,792,54$ & $88.34 \%$ \\
\hline Control 2 & $113,657,819$ & $102,102,063$ & $87.89 \%$ \\
\hline Control 3 & $413,589,26$ & $387,238,58$ & $88.54 \%$ \\
\hline Challenged 1 & $915,321,41$ & $872,570,38$ & $90.42 \%$ \\
\hline Challenged 2 & $145,682,503$ & $137,041,556$ & $88.67 \%$ \\
\hline Challenged 3 & $140,667,468$ & $125,491,032$ & $90.23 \%$ \\
\hline
\end{tabular}

Table 1: Summary statistics of RNA-Seq output. The mapping percentage was calculated as the number of reads mapped to the reference genome divided by the number of cleaned count reads

Based on functional importance genes known to be involved in cell death 22,38 , ten genes were selected from our DEGs list to validate the RNA-Seq data. The selected genes were covered the full range of $\log _{2}$ fold change ( $\log _{2}$ FC) and measured their expression level in qPCRs. The $\log _{2}$ FC obtained from RNA-Seq data analysis was compared to the $\log _{2}$ FC obtained in qPCRs. Figure 2 shows a comparison between the result of qPCR and RNA-Seq data. The expression patterns obtained from qPCR results for all ten selected genes were similar to their patterns from RNA-Seq analysis, with a correlation coefficient (R) of 0.98 . These results confirming the reliability of the RNA-Seq data for gene expression patterns. Functional analysis of 6361 DEGs detected in NDV challenged chickens with IPA indicated the roles in immune response (specifically in early stage of splenic response) to the infection for most of top DEGs with zscore more than 3 (Table 2). Due to the use of human- and mouse-based database by IPA for analysis, the types and the functions of some of chicken genes have not been indicated properly. Further investigation into the functions of these uncharacterised proteins and genes would be useful to provide more insight into their contribution to infection. A list of DEGs with consistent responses in expression to NDV infection was released by Zhang et al. (2020) ${ }^{20}$. Comparison of DEGs in our study with Zhang et al revealed 23 shared genes (Table 3). Thirteen (56\%) of these shared genes had consistent expression change in our study and study of spleen of Hy-Line Brown birds ${ }^{20}$, spleen 19,39,40, Harderian gland ${ }^{17,41}$, lung ${ }^{15}$, Trachea ${ }^{16}$ or embryo ${ }^{42}$ of Fayoumi or Leghorn chickens challenged with lentogenic NDV. Particularly, interferon induced protein with tetratricopeptide repeats 5 (IFIT5) showed significant upregulation in the spleen of all chickens challenged with virulent and non-virulent NDVs. However, 10 (44\%) of these shared significant DEGs had opposite regulation in our study, suggesting a quite different response to virulent NDV infections. 


\begin{tabular}{|c|c|c|c|c|c|}
\hline Symbol & Function of Gene ${ }^{a}$ & $\operatorname{LFC}^{b}$ & FDR $^{c}$ & Type(s) & HGNC $^{d}$ \\
\hline AGT & angiotensinogen & 14.366 & 0.0009 & growth factor & 183 \\
\hline CAMK2A & calcium/calmodulin dependent protein kinase II alpha & 10.169 & 0.0008 & kinase & 815 \\
\hline CAMKV & CaM kinase like vesicle associated & 10.958 & 0.0101 & kinase & 79012 \\
\hline ELOVL2 & ELOVL fatty acid elongase 2 & 10.402 & 0.0019 & enzyme & 54898 \\
\hline GABRA3 & gamma-aminobutyric acid type A receptor subunit alpha3 & 10.432 & 0.0006 & ion channel & 2556 \\
\hline GFAP & glial fibrillary acidic protein & 12.885 & 0.0004 & other & 2670 \\
\hline GPM6A & glycoprotein M6A & 12.11 & 0.0020 & ion channel & 2823 \\
\hline $\operatorname{IRX1}$ & iroquois homeobox 1 & 10.723 & 0.0026 & transcription regulator & 79192 \\
\hline MMD2 & monocyte to macrophage differentiation associated 2 & 11.067 & 0.0016 & kinase & 221938 \\
\hline PACSIN1 & protein kinase $\mathrm{C}$ and casein kinase substrate in neurons 1 & 10.774 & 0.0009 & kinase & 29993 \\
\hline$P A D / 3$ & peptidyl arginine deiminase 3 & 10.267 & 0.0005 & enzyme & 51702 \\
\hline PLP1 & proteolipid protein 1 & 13.157 & 0.0003 & other & 5354 \\
\hline SLC15A2 & solute carrier family 15 member 2 & 10.478 & 0.0022 & transporter & 6565 \\
\hline SLC1A3 & solute carrier family 1 member 3 & 13.277 & 0.0011 & transporter & 6507 \\
\hline SLC6A11 & solute carrier family 6 member 11 & 11.937 & 0.0014 & transporter & 6538 \\
\hline TTLL2 & tubulin tyrosine ligase like 2 & 10.69 & 0.0016 & other & 83887 \\
\hline
\end{tabular}

Table 2 . The list of the genes that significantly ( $z$-score $>3$ ) affected at the challenged group.

a IPA software was used to obtain gene's function from the transcript identifier

b LFC, Log 2 fold change.

c FDR, false discovery rate.

d HGNC, Human Gene Nomenclature Committee 


\begin{tabular}{|c|c|c|c|}
\hline $\begin{array}{l}\text { Gene } \\
\text { Name }\end{array}$ & Function & $\begin{array}{l}\text { LFC in this } \\
\text { study at } 2 \text { dpi }\end{array}$ & Comparison with Response in other NDV studies \\
\hline PLCXD1 & $\begin{array}{l}\text { phosphatidylinositol specific phospholipase } \mathrm{CX} \\
\text { domain containing } 1\end{array}$ & 0.47 & Consistent with Spleen of $\mathrm{Hy}$-Line Brown at $2 \mathrm{dpi}^{20}$ and Harderian gland of Leghorn at $6 \mathrm{dpi}{ }^{17}$ \\
\hline SLBP & stem-loop binding protein & 0.85 & Consistent with Spleen of $\mathrm{Hy}$-Line Brown at $2 \mathrm{dpi}^{20}$ and Spleen ${ }^{19}$ and trachea ${ }^{16}$ of Leghom at $2 \mathrm{dpi}$ \\
\hline OSTM1 & $\begin{array}{l}\text { osteoclastogenesis associated transmembrane } \\
\text { protein } 1\end{array}$ & 1.00 & Consistent with Spleen of $\mathrm{Hy}$-Line Brown at $2 \mathrm{dpi}^{20}$ and Trachea of Leghorn at $2 \mathrm{dpi}^{16}$ \\
\hline DRAM1 & DNA damage regulated autophagy modulator 1 & 1.40 & Consistent with Spleen of $\mathrm{Hy}$-Line Brown at $2 \mathrm{dpi}^{20}$ and Trachea of Fayoumi and Leghorn at $2 \mathrm{dpi}{ }^{16}$ \\
\hline PARP12 & poly(ADP-ribose) polymerase family member 12 & 1.48 & Consistent with Spleen of $\mathrm{Hy}$-Line Brown at $2 \mathrm{dpi}^{20}$ and Harderian gland at 2 and $6 \mathrm{dpi}^{77}$, in spleen at $2 \mathrm{dpi}^{19}$ in Leghom \\
\hline SNX10 & sorting nexin 10 & 1.90 & Consistent with Spleen of $\mathrm{Hy}$-Line Brown at $2 \mathrm{dpi}^{20}$ and Spleen ${ }^{19}$ and trachea ${ }^{16}$ of Leghom at $2 \mathrm{dpi}$ \\
\hline IFIT5 & $\begin{array}{l}\text { interferon induced protein with tetratricopeptide } \\
\text { repeats } 5\end{array}$ & 6.09 & Consistent with Spleen of Hy-Line Brown at $2 \mathrm{dpi}^{20}$ and Spleen of Leghorn at $1^{30}, 2{ }^{19,39}$ and $6 \mathrm{dpi}^{19}$, and of Fayoumi at $2 \mathrm{dpi}{ }^{19}$ \\
\hline$P 2 R \times 1$ & purinergic receptor $\mathrm{P} 2 \mathrm{X} 1$ & -5.62 & Consistent with Spleen of $\mathrm{Hy}$-Line Brown at $2 \mathrm{dpi}^{20}$ and Lung of Fayoumi at $10 \mathrm{dpi}{ }^{15}$ \\
\hline KAZALD1 & Kazal type serine peptidase inhibitor domain 1 & -3.46 & Consistent with Spleen of $\mathrm{Hy}$-Line Brown at $2 \mathrm{dpi}^{20}$ and Trachea of Leghorn at $6 \mathrm{dpi}^{16}$ \\
\hline HPSE2 & heparanase 2 (inactive) & -2.61 & Consistent vith Spleen of Hy-Line Brown at $2 \mathrm{dpi}^{20}$ and Trachea of Leghorn at $2 \mathrm{dpi}^{15}$ \\
\hline UROC1 & urocanate hydratase 1 & -2.52 & Consistent with Spleen of $\mathrm{Hy}$-Line Brown at $2 \mathrm{dpi}^{20}$ and Harderian gland of Leghorn at $6 \mathrm{dpi}{ }^{17}$ \\
\hline ROR1 & receptor tyrosine kinase like orphan receptor 1 & -1.66 & Consistent with Spleen of $\mathrm{Hy}$-Line Brown at $2 \mathrm{dpi}^{20}$ and Lung of Fayoumi at $2 \mathrm{dpi}{ }^{15}$ \\
\hline FSHR & follicle stimulating hormone receptor & -0.46 & Consistent with Spleen of $\mathrm{Hy}$-Line Brown at $2 \mathrm{dpi}^{20}$ and Trachea of Leghorn at $6 \mathrm{dpi}^{16}$ \\
\hline$A / C D A$ & activation induced cytidine deaminase & -8.98 & Inconsistent with Spleen of Hy-Line Brown at $2 \mathrm{dpi}^{20}$ and Trachea of Leghorn at $6 \mathrm{dpi}{ }^{16}$ \\
\hline P2RY8 & P2Y receptor family member 8 & -3.24 & Inconsistent with Spleen of Hy-Line Brown at $2 \mathrm{dpi}^{20}$ and Harderian gland at $6 \mathrm{dpi}{ }^{17}$ and trachea at 2 and $6 \mathrm{dpi}{ }^{18}$ in Leghorn \\
\hline ARHGAP15 & Rho GTPase activating protein 15 & -1.85 & Inconsistent with Spleen of Hy-Line Brown at $2 \mathrm{dpi}^{20}$ and Trachea of Fayoumi at $2 \mathrm{dpi}$ and Leghorn at 2 and $6 \mathrm{dpi}{ }^{16}$ \\
\hline ASNS & asparagine synthetase (glutamine-hydrolyzing) & -0.58 & Inconsistent with Spleen of Hy-Line Brown at $2 \mathrm{dpi}^{20}$ and Harderian gland of Leghorn at $6 \mathrm{dpi}{ }^{17}$ \\
\hline TRIM24 & tripartite motif containing 24 & -0.57 & Inconsistent with Spleen of Hy-Line Brown at $2 \mathrm{dpi}^{20}$ and Trachea of Leghorn at $6 \mathrm{dpi}{ }^{\text {th }}$ \\
\hline CDC42SE2 & CDC42 small effector 2 & -0.37 & Inconsistent with Spleen of Hy-Line Brown at $2 \mathrm{dpi}^{20}$ and Trachea of Fayoumi at $2 \mathrm{dpi}^{16}$ \\
\hline BFAR & bifunctional apoptosis regulator & -0.36 & Inconsistent with Spleen of Hy-Line Brown at $2 \mathrm{dpi}^{20}$ and Trachea of Fayoumi and Leghom at $2 \mathrm{dpi}^{16}$ \\
\hline ST3GAL4 & ST3 beta-galactoside alpha-2,3-sialyltransferase 4 & 0.28 & Inconsistent with Spleen of Hy-Line Brown at $2 \mathrm{dpi}^{201}$ and Harderian gland of Leghorn at $6 \mathrm{dpi}$ under heat stress ${ }^{41}$ \\
\hline MYH10 & myosin heavy chain 10 & 0.29 & Inconsistent with Spleen of Hy-Line Brown at $2 \mathrm{dpi}^{20}$ and Trachea of Leghorn at $6 \mathrm{dpi}{ }^{16}$ \\
\hline EPHB1 & EPH receptor B1 & 0.32 & Inconsistent with Spleen of Hy-Line Brown ${ }^{20}$ and Trachea of Fayoumi at $2 \mathrm{dpi}{ }^{\text {th }}$ \\
\hline
\end{tabular}

Table 3. Comparison of DEGs response to NDV in the present study and other in vivo NDV infection studies. LFC stands for log 2 fold change.

\section{Ingenuity Pathway Analysis of differentially Expressed Genes}

The DEGs list created from transcriptome analysis ( $p<0.05$, log2 fold change $\geq 1)$ was used as input for IPA analysis. IPA uses a Fisher's exact test p-value cut of 0.05 and an absolute z-score cut-off of 2 or greater for pathways to consider them as significantly enriched. In this study, we focused on the pathways engaged in cell death and injury pathways. Overall canonical pathways, upstream regulators, disease and biological functions that were predicted by IPA to be activated are shown in Figure 3. Inhibition of IL2 and downregulation of EIF2 signalling as an upstream regulator, resulted in the inhibition of B lymphocytes, the number of lymphatic system cells, mononuclear leukocytes and proliferation of lymphatic system cells. Inhibition of these processes may result in depletion in immune cells and lymphatic tissue destruction in spleen observed in spleen in challenged chicken with virulent NDV-GVII. IPA predicted upregulation of ATF4 that resulted in activation of synaptogenesis signalling pathway, CREB signalling in neurons and neuropathic pain signalling in dorsal horn neurons in our analysis. Several pathways were significantly impacted by the challenge with virulent NDV as predicted by IPA. Top pathways are shown in Figure 4 and a list of all altered pathways provided in Supplementary Table S3. Overall, many of these pathways lead to cell death and immune response to infection. In particular, Elf2 and mTOR signalling was on top of our downregulated pathways. mTOR signalling activates autophagy and increased autophagy assistances NDV replication ${ }^{43}$. EIF2 pathway results in inhibition of viral replication through inhibition of translation of viral proteins and increased apoptosis in infected cells ${ }^{44}$. Reduced autophagy and increased apoptosis would help infected cells with the virus. IPA also predicted activation of signalling by Rho family GTPases, CREB signalling in Neurons and synaptogenesis pathway that are mainly related to the neuropathogenesis of this strain. 
Zhang et al. (2020) study has recently reported 31 pathways with consistent expression response to nonvirulent strains of $\mathrm{NDV}^{20}$. Comparison of predicted pathways in our study with impacted pathways by lentogenic NDVs, revealed 16 shared pathways (Table 4). Significant downregulation (z score <-2) of 5 $(31 \%)$ of the shared pathways in our study was in agreement with a study of NDV infection caused by a lentogenic strain in spleens of Hy-Line Brown chickens ${ }^{20}$. However, significant activation of these pathways has been reported in lung ${ }^{15}$, Harderian gland ${ }^{17}$ and trachea ${ }^{16}$ of Fayoumi and Leghorn chicken challenged with lentogenic strain of NDV. Eleven (68\%) of these shared pathways also haven't been significantly impacted ( $z$ score $>-2$ or $<2$ ) by virulent NDV in our study, while Zhang et al. (2020) and Deist et al. (2017) studies reported significant activation and inhibition of these pathways respectively in the response of lentogenic NDV. These findings suggest a different response of the immune system to virulent and non-virulent NDV in different tissues. Analysis of disease biomarkers in our results revealed functions associated with virulent NDV (Table 5). A decrease in proliferation of lymphatic system cells, quantity of B lymphocytes and quantity of mononuclear leukocytes are predicted by IPA using Ingenuity Knowledge Base approach ${ }^{45}$. Inhibition of these pathways together may contribute to the massive depletion of lymphoid cells in spleen observed in experimentally infected birds. However, an increase in microtubule dynamics is also predicted to be associated with NDV infection. Upregulation of key genes such as angiotensinogen ( $A G T)$ and proteolipid protein 1 (PLP1) contributed to both activated and inhibited pathways. 


\begin{tabular}{|c|c|c|c|}
\hline \multirow[t]{2}{*}{ zPathways } & \multirow{2}{*}{$\begin{array}{c}\text { Z-Score } \\
\text { (current } \\
\text { study) }\end{array}$} & \multicolumn{2}{|c|}{$\begin{array}{l}\text { IPA prediction in other studies using non- } \\
\text { virulent NDV }\end{array}$} \\
\hline & & Inhibition & Activation \\
\hline TNFR2 Signalling & -3.00 & Spleen ${ }^{20}$ & Trachea $^{16}$ \\
\hline TNFR1 Signalling & -2.32 & Spleen ${ }^{20}$ & Trachea ${ }^{16}$ \\
\hline GP6 Signalling Pathway & -2.23 & Spleen ${ }^{20}$ & Harderian gland ${ }^{17}$ \\
\hline Leukocyte Extravasation Signalling & -2.21 & Spleen ${ }^{20}$ & Trachea ${ }^{16}$ \\
\hline $\begin{array}{l}\text { Production of Nitric Oxide and Reactive Oxygen } \\
\text { Species in Macrophages }\end{array}$ & -2.02 & Spleen $^{20}$ & Trachea $^{16}$ \\
\hline $\begin{array}{l}\text { Fcy Receptor-mediated Phagocytosis in Macrophages } \\
\text { and Monocytes }\end{array}$ & -1.54 & Spleen ${ }^{20}$ & Trachea $^{16}$ \\
\hline Tec Kinase Signalling & -1.50 & Spleen ${ }^{20}$ & Lung ${ }^{15}$, trachea ${ }^{16}$ \\
\hline B Cell Receptor Signalling & -1.13 & Spleen ${ }^{20}$ & trachea $^{16}$ \\
\hline Integrin Signalling & -0.92 & Spleen ${ }^{20}$ & Lung ${ }^{15}$ \\
\hline IL-8 Signalling & -0.53 & Spleen ${ }^{20}$ & Lung ${ }^{15}$, trachea ${ }^{16}$ \\
\hline CD40 Signalling & -0.42 & Spleen $^{20}$ & Trachea $^{16}$ \\
\hline Thrombin Signalling & -0.12 & Spleen ${ }^{20}$ & Lung ${ }^{15}$ \\
\hline IL-6 Signalling & 0.18 & Spleen ${ }^{20}$ & Trachea $^{16}$ \\
\hline P2y Purigenic Receptor Signalling Pathway & 0.88 & Spleen ${ }^{20}$ & Lung ${ }^{15}$ \\
\hline Relaxin Signalling & 1.00 & Spleen ${ }^{20}$ & Lung ${ }^{15}$ \\
\hline Ephrin Receptor Signalling & 1.76 & Spleen ${ }^{20}$ & Lung ${ }^{15}$ \\
\hline
\end{tabular}

Table 4. Comparison of predicted pathways by IPA in current study with other studies that investigated the response to NDV infection. Minus z-score means inhibition and positive z-score means activation.

\begin{tabular}{|l|l|l|l|}
\hline Disease and functions & Contributed DEGs for prediction & z-score & No. \\
\hline $\begin{array}{l}\text { Proliferation of lymphatic } \\
\text { system cells }\end{array}$ & $\begin{array}{l}\text { PLP1, SOX2, GAD2, UNC119, APOH, GAD1, MBP, ADCYAP1, } \\
\text { FOXJ1, TYR }\end{array}$ & -3.571 & 168 \\
\hline Quantity of B lymphocytes & $\begin{array}{l}\text { SLCO1A2, F3, ST6GALNAC2, FZD9, HGF, PLCD1, ESR1, BST1, } \\
\text { ABL1, STAT1 }\end{array}$ & -2.769 & 93 \\
\hline Quantity of lymphocytes tissue & $\begin{array}{l}\text { GAD2, NPY, SLC4A4, FADS2, FOXC2, PCSK1, YES1, ESR1 } \\
\text { ABL1, MX11 }\end{array}$ & -2.402 & 89 \\
\hline $\begin{array}{l}\text { Quantity of mononuclear } \\
\text { leukocytes }\end{array}$ & $\begin{array}{l}\text { AGT, PLP1, GAD2, MBP, ADCYAP1, SLCO1A2, F3 } \\
\text { SNCA, NPY, SLC4A4 }\end{array}$ & -2.785 & 172 \\
\hline Microtubule dynamics & $\begin{array}{l}\text { AGT, GPM6A, PACSIN1, CAMK2A, SOX2, PHGDH, RFX4, } \\
\text { SLC39A12, GRIN1, SNCB }\end{array}$ & 4.311 & 245 \\
\hline
\end{tabular}

Table 5. Top disease and biological function predicted by IPA to be associated with NDV infection. Bold italic and italic text indicates upregulated and downregulated DEGs respectively. Genes are sorted ascendingly from left to right based on their fold change. No. means the number of DEGs in our data contributed to disease production.

\section{Discussion}


Understanding the molecular basis of pathogenesis of newly emerged NDVs will provide more reliable information on how these viruses produce unique pathological features in infected chickens, even in vaccinated flocks ${ }^{9}$. Gene expression pattern analysis helps to understand the virus and host interactions. Several in vivo and in vitro studies investigated gene expression in different tissues from experimentally infected chickens with different genotypes of NDV 15-17,19-21. However, the molecular pathogenesis of genotype VII of NDVs has not been well described especially in in vivo studies. Herein, RNA-Seq and bioinformatics analyses were employed to study spleen transcriptome in experimentally infected birds with highly virulent NDV-GVII.

The spleen, as a primary lymphoid organ in birds, plays a critical role in early stage of the host defence response to NDV. Gene expression profile analysis of spleen provides insights into host immune defence. Splenic cells produce alpha and beta interferon and interleukin 6 (IL-6) within the first six hours of exposure of chickens to virulent NDV ${ }^{46}$. Spleen also has an important role in T cell immune response and lymphocyte transformation in immune response to NDV infection ${ }^{47}$.

In this study, a higher number of differentially expressed genes ( $>6000)$ were found when compared to in vivo studies of nonvirulent NDV ${ }^{15,48}$. Liu et al. (2018) reported 8433 DEGs in chick embryo fibroblasts (CEFs) infected with virulent Herts/33 strain ${ }^{21}$. Regardless of the fundamental differences with our study, both studies showed similar patterns of gene expression with high number of DEGs in the response to virulent NDVs.

IPA predicted inhibition of MTOR and EIF2 signalling and placed them on top 10 pathways altered by NDV infection in our list. mTOR signalling regulates CD8 T cell differentiation ${ }^{49}$, and induces Toll-kill receptor-mediated IFNA1 in plasmacytoid dendritic cells and has a negative control role in autophagymediated cell death after viral infection ${ }^{50,51}$. mTOR signalling activates autophagy and an increased autophagy benefits NDV replication ${ }^{43}$. EIF2 signalling has been known as a viral replication inhibitor and proinflammatory cytokine expression regulator ${ }^{52}$. EIF2 pathways inhibits translation of virus and increases apoptosis in infected cells, resulting in inhibition of viral replication ${ }^{44}$. Downregulation of these pathways indicates the host's immune response in preventing of viral replication in infected cells. Deist et al. (2017) reported downregulation of EIF2 pathway in lung of challenged Fayoumis with lentogenic NDV at $10 \mathrm{dpi}{ }^{15}$. However, different pattern of activation of EIF2 signalling pathway were reported in trachea and spleen of challenged birds with non-virulent NDV at $2 \mathrm{dpi}{ }^{16}$, and Viral shedding were not reported in these studies. Considering the crucial role of these pathways in inhibition of viral replication, downregulation of these pathways along with considerable virus shedding in our challenged group may indicate altered strategies used by the host to defend itself from the virulent NDVs.

Our IPA analysis also indicated the downregulation of some shared immune pathways with other in vivo NDV infections ${ }^{20}$. IL-8 signalling has a vital role during infectious disease by regulation of chemotaxis and activation of neutrophils ${ }^{53}$. IL-15 production also facilitates homeostasis, development of natural killer cells and CD8 T cells during anti-viral response ${ }^{54}$. Tec kinase signalling pathway has also critical 
role in response to viral infection and is essential for differentiation and development of CD4+ ${ }^{55}$ and $\mathrm{CD} 8+\mathrm{T}$ cell ${ }^{56}$. IL-2 has a critical role in activation of NK cells, lymphocyte proliferation and clearance of intracellular pathogens in chickens ${ }^{57,58}$. Inhibition of these share pathways and especially IL-2, as a key upstream regulator in our study, suggests a suppressed immune response caused by this newly emerged NDV-GVII.

Most of the top upregulated genes indicated in our RNA transcriptome were involved in the immune response to the infection in spleen. AGT and PLP1 both are associated with increased quantity of cytotoxic CD8+ T-cell ${ }^{59}$. GPM6A has a role in the expression of human GPM6A mRNA in marginal-zone $B$ lymphocytes expressing human CD27 protein and human IgD complex ${ }^{60}$. Upregulation of AGT and PLP1 in our study contributed in disease production that resulted in massive depletion of spleen.

Previous studies reported tissue-specific immune response ${ }^{61}$ and breed specific immune gene expression in chickens ${ }^{62}$. Our results indicate small portion and also opposite regulation of shared significant DEGs with previous in vivo studies of lentogenic NDV. These differences emphasise virulence as an indicator of immune response during viral infection.

Our result shows activation of pathways that regulate cellular actin such as signalling by Rho family GTPases resulting an activated microtubule dynamics pathway. The critical role of this pathway in cellcell fusion and syncytium formation in pathogenesis of paramyxoviruses that helps virus entry to the host cell has been reported by Gower et al. (2015) ${ }^{63}$. These results may suggest that NDV as a paramyxovirus, facilitates viral replication and infection by activation of this pathway.

IPA analysis also pointed out activation of synaptogenesis signalling in our results. This pathway plays a critical role in development of nervous system by regulation of synapse formation between neurons ${ }^{64}$. Our results also indicate a decreased quantity of lymphoid tissue and inhibited proliferation of lymphatic system cells. This result was in contrast with Zhang et al. (2020) that used lentogenic NDV in their challenge experiment ${ }^{20}$. Activation of pathways that results in development of synapses in nervous system and depletion of lymphoid tissue suggests possible shift in tissue tropism of this strain from a neurotropic velogenic pathogen to a lymphotropic virus. More in situ detection and analysis of viral antigens in different tissues of infected birds is necessary for comprehensively understanding of the tissue tropism of this newly emerged virulent NDV.

On the other hand, our results indicate genes with consistent expression regulation in different studies with many varied experimental factors such as virulence of virus, tissue and breed and time point sampling. This suggests a universal role of these genes in immune response to NDV. One of the most significant genes is IFIT5, which is an interferon-stimulated gene and its critical role for innate immune defence against virus has been confirmed ${ }^{65}$. IFIT5 recognises and inhibits translation of viral RNA bearing a $5^{\prime}$-triphosphate ${ }^{66}$, and also has a key regulator role in activation of B-cells by positive regulation of nuclear factor kappa-light-chain-enhancer in NF-KB signalling pathway ${ }^{67}$. Overexpression of 
IFIT5 in transgenic chickens showed significant enhanced resistance to avian influenza and velogenic NDV ${ }^{68}$. Consistent up-regulation of IFIT 5 in the spleen of all chickens challenged with virulent and nonvirulent NDV indicates critical role of this gene in splenic immune response to viral infections.

Compared to the great importance of NDV to the poultry industry and its effects on international trade, there is a relatively modest number of published infectious challenge experiments in which virulent virus has been administered to chickens. In vivo experiments using virulent NDV require specialised animal PC3 facilities which are expensive to build and operate. Rapid progression of induced disease can make it difficult to sample birds over multiple days post infection. In the present study, we had intended to sample birds at 48 and 72 hours post-inoculation. However, we decided to humanely kill them all at 48 hours post challenge due to severe clinical signs of disease and high mortality that were already increasing within 24 hours. The reduced quality of RNA extracted from infected birds in comparison with healthy birds was another limitation of this study that was an unavoidable consequence of destruction of the host transcriptome during the acute phase of paramyxovirus infection ${ }^{69}$.

\section{Conclusion}

This is the first study of gene expression profiling of spleen tissue of experimentally infected chickens with a virulent NDV-GVII. In conclusion, we observed extensive alteration of gene expression in response to this strain in the spleen of chickens. Multiple comparisons of gene expression profile of spleen between this study and previous studies of lentogenic NDV infections indicates differences between DEGs and activation pathway patterns, indicating the role of virulence of virus in immune responses. Activation of autophagy-mediated cell death, lymphotropic and synaptogenesis development pathways after viral infection suggests a new tissue tropism for genotype VII NDVs. Further in vivo study of these virulent NDV strains in chickens is needed to more comprehensively reveal the molecular pathogenesis of these newly emerged virulent strains of NDV.

\section{Materials And Methods}

\section{Challenge experiment}

Animal experiments were performed at the Indonesian research centre for veterinary science (Bbalitvet), Bogor, Indonesia. The animal ethics was approved by the research and animal ethics committee of Bbalitvet institute with reference number of $A H / 2015 / 003$. An experienced veterinarian managed the challenge experiment in accordance with the National Health and Medical Research Council (NHMRC) of Australia and the Animal Research Reporting of In Vivo Experiments (ARRIVE) guidelines 2.0. Twenty, 1day old SPF broiler Ross chickens sourced from Caprifarmindo Laboratories (Bandung, Indonesia) were divided into two groups of 10 and raised in isolator units at biosafety level 3 (BLS3) biocontainment at Bbalitvet. Chickens were allocated randomly into two isolators and tagged individually. At 35 days of age, the birds were inoculated by intraocular and intranasal instillation with $100 \mu \mathrm{L}$ of 100 EID $50{ }^{70,71}$ of live 
Mega strain of NDV (accession number of MN688613) ${ }^{12}$. One group of 10 birds was kept as a negative control in isolator 2 .

\section{Tissue collection and RNA extraction}

Following viral challenge, birds were monitored twice a day for clinical signs of ND. Dead birds were collected, and those with severe clinical signs of disease were euthanised and counted as mortalities for that day. Due to death or severe sickness of chickens in the challenged group, the experiment was terminated at 2 day post infection ( $2 \mathrm{dpi}$ ), and the birds in all groups were euthanised by cervical dislocation. After opening of the carcass, the spleen was removed, briefly diced and placed in RNAlater (Ambion, Thermo Fisher, MA, USA) for RNA extraction. In total, twenty RNA samples from spleens of challenged and control groups were isolated using a mirVana miRNA isolation kit (Ambion, Thermo Fisher, Lithuania). To remove the genomic DNA residue, the isolated RNA was treated with DNase using a DNA-free kit (Thermo Fisher Scientific, Carlsbad, CA, USA). RNA quality was assessed by Agilent 2200 TapeStation instrument, (Agilent Technologies, Santa Clara, CA, USA) and confirmed as RNA Integrity Number $(\mathrm{RIN})>5$ for all samples. 1

\section{Detection of virus shedding in challenged and control chickens}

From each chicken, a cloacal swab sample was taken and viral RNA was extracted from cloacal swab samples using QIAamp Viral RNA Mini kit (Qiagen, Louisville, KY, USA) and quantified using NanoDrop 1000 Spectrophotometer (Thermo Fisher Scientific, Carlsbad, CA, USA). Five microliter of extracted RNA was converted to cDNA using a QuantiTect Reverse Transcription Kit (Qiagen, Louisville, KY, USA) as per manufacturer's instruction. Absolute quantification for detection of viral load by qPCR was performed using NDV-Fusion Forward: 5' AAAGTGGTGACACAGGTCGG 3', and NDV-Fusion Reverse primer: 5' CCGATGTATTGCCGCTCAAG 3', generating a 145 bp amplicon. Real-time polymerase chain reaction (RTPCR) was carried out using QuantiFast SYBR ${ }^{\circledR}$ Green PCR Kit (Qiagen, Louisville, KY, USA). The reaction was run in an Illumina, Eco Real-Time PCR machine (California U.S.A.) with initial denaturation at $95^{\circ} \mathrm{C}$ for 3 minutes ( $\mathrm{min}$ ) followed by 40 cycles of $95^{\circ} \mathrm{C}$ for 10 seconds (s) and $60^{\circ} \mathrm{C}$ for $30 \mathrm{~s}$. Each qPCR reaction was repeated three times in triplicate. The $\mathrm{Ct}$ values greater than 35 in viral samples were considered negative ${ }^{72}$. One-way analysis of variance (ANOVA) was undertaken to test for mean differences in CT values. The results were analysed in IBM SPSS (v 26.0; SPSS Inc., Chicago, IL).

\section{RNA sequencing}

After the initial assessments and the quality control of the RNA samples, three RNA samples from the challenged group and three RNA samples from the negative control group with RIN $>5$ were selected for the further analysis. The selected samples were submitted to Australian Genome Research Facility for RNA sequencing. Sequencing libraries were prepared with the TruSeq RNA Library Predation kit as per the manufacturer's protocol and sequenced on Illumina NovaSeq 6000 platform.

\section{Transcriptome analysis}

Page 14/26 
Raw RNA-Seq paired end reads were checked for quality using FASTQC v0.11.4 ${ }^{73}$ and trimmed with TrimGalore v0.4. $2^{74}$ to a minimum length of $150 \mathrm{bp}$ per read and Phred score of 10 . Sequencing adapters were removed with AdapterRemoval v2.2.1 ${ }^{75}$. Cleaned reads were mapped to the chicken reference genome (GRCg6a) using Hisat2 v2.1.0 ${ }^{76}$. Mapped reads were sorted with SAMtools v1.8 ${ }^{77}$. Then, sorted mapped reads were summarised using FeatureCounts ${ }^{78}$ at the gene level using Ensembl annotation version 97. The Voom-limma pipeline ${ }^{79,80}$ was used to analyse samples grouped by infection status using the gene-level read counts as input. Briefly, the pipeline involved the removal of lowly expressed genes, i.e. genes meeting the requirement of count per million (CPM) more than one in at least three samples. The counts were normalised by log-transforming the counts per million to standardise for differences in library size. Counts were also normalised using trimmed mean of $M$ values (TMM) method 81 to avoid bias from different coverage, and samples and individual observational level of each expressed genes were weighted using Voom ${ }^{80}$ to account for heterogeneity in their expression level. Moderated t-statistics tests were used to define differential expression levels between samples. Differentially expressed genes (DEGs) between groups with different infection status were tested and ranked based on the false discovery rate (FDR) less than 0.05 .

\section{Pathway analysis of differentially expressed genes}

Differentially expressed genes (DEGs) with FDR $<0.05$ were analysed using the Ingenuity Pathway Analysis software (IPA, QIAGEN, Redwood City, CA, USA), and pathways or functions with z-score $>2$ were considered to be activated or inhibited ${ }^{45}$.

\section{Validation of RNA-Seq data}

Applied Biosystems Real-Time PCR System comparative $\mathrm{Ct}(\Delta \Delta \mathrm{Ct})$ assay was used to validate RNA-Seq results. Gene expression measured in all tissues samples in challenged and control groups $(n=20)$. For each sample, cDNA was prepared from $1 \mu \mathrm{g}$ of RNA using the QuantiTect Reverse Transcription Kit (Qiagen, Melbourne, Australia) according to the manufacturer's protocols. PowerTrack SYBR Green Master Mix (Thermo Fisher Scientific, Australia) was used to prepare PCR master mix in a $20 \mu \mathrm{L}$ reaction volume as per the manufacturer's protocol and $2 \mu \mathrm{L}$ of the CDNA was added into each reaction well (in triplicate) using a robot (Ep Motion 5075 Robot system, Eppendorf AG, Hamburg, Germany). Thermocycling conditions in ABI Quant StudioTM 6 Flex thermal cycler (Thermo Fisher Scientific, Australia) were polymerase activation at $95^{\circ} \mathrm{C}$ for $2 \mathrm{~min}, 40$ cycles of denaturation at $95^{\circ} \mathrm{C}$ for $15 \mathrm{~s}$, annealing at $60{ }^{\circ} \mathrm{C}$ for $60 \mathrm{~s}$. A melting curve step from a ramp of 50 to $99^{\circ} \mathrm{C}$ was included to assess the specificity of amplification. Based on their log2 FC (LFC) in RNA-Seq analysis, we selected ten genes that cover the full range of LFC in the comparisons between treatments and control group, and the functional importance of each gene in cell death has also been considered ${ }^{22,38}$. These primers are listed in Table 6. The primers were designed by NCBI primer tool with amplicons around $100 \mathrm{bp}$ and spanning multiple exons specified also applied to avoid amplification of genomic DNA. uMelt web-based tool used for prediction of DNA melting curves and denaturation profile of PCR products for assessment of specific 
amplification of primers ${ }^{82}$. Amplifications of a series of five, ten-fold dilution of cDNA used for determination of PCR amplification efficiencies and correlation coefficients (R) ${ }^{83-86}$. The geometric mean of Ct values of YWHAZ and TBP housekeeping genes, that are more stably expressed in the spleen of chicken challenged with pathogens ${ }^{87,88}$, were used for normalisation of the data. Data were analysed using the Quant Studio Real-Time PCR Analysis software. Replicates of the same sample showing a shifted peak in melting curves were removed. Gene expression was compared between control and treatment groups using the $2(-\Delta \Delta \mathrm{Ct})$ method, and Pearson Correlation Coefficient between LFC in qPCR assay and RNA-Seq data were calculated, using the GraphPad prism software version 8.4.2 (GraphPad Software, LLC, San Diego, CA, USA).

\begin{tabular}{|c|c|c|c|c|c|c|c|c|c|}
\hline Gene Symbol & Primer sequence $\left(5^{\prime}-3\right)$ & Exon junction (bp) & $\begin{array}{l}\text { Fragment } \\
\text { size (bp) }\end{array}$ & $\begin{array}{l}\text { Annealing } \\
{ }^{\circ} \mathrm{C}\end{array}$ & $\begin{array}{l}\text { PCR } \\
\text { Efficiency }(\%)\end{array}$ & $\begin{array}{l}\text { Correlation } \\
\text { coefficient } \\
\text { (R) }\end{array}$ & Slop & NCBI accession & Reference \\
\hline \multirow[t]{2}{*}{$\overline{A P A F 1}$} & F: GGTCAATTGCTGCCAGTTCA & \multirow[t]{2}{*}{$2316 / 2317$ (reverse primer) } & \multirow[t]{2}{*}{94} & \multirow[t]{2}{*}{60} & \multirow[t]{2}{*}{129} & \multirow[t]{2}{*}{0.9539} & \multirow[t]{2}{*}{-2.76} & \multirow[t]{2}{*}{ XM_416167.6 } & \multirow[t]{2}{*}{ this study } \\
\hline & R: TCCTTCAAATCCCAAAGTTTGAT & & & & & & & & \\
\hline \multirow[t]{2}{*}{ CASP3 } & F: GCAGACAGTGGACCAGATGA & \multirow[t]{2}{*}{ 90/91 (reverse primer) } & \multirow[t]{2}{*}{94} & \multirow[t]{2}{*}{60} & \multirow[t]{2}{*}{166} & \multirow[t]{2}{*}{0.9502} & \multirow[t]{2}{*}{-2.349} & \multirow[t]{2}{*}{ XM_015276122.2 } & \multirow[t]{2}{*}{ this study } \\
\hline & R: AGGAGTAGTAGCCTGGAGCA & & & & & & & & \\
\hline \multirow[t]{2}{*}{ CYCS } & F: CGTGGGCGCATTTACTGACA & \multirow[t]{2}{*}{ 107/108 (forward primer) } & \multirow[t]{2}{*}{81} & \multirow[t]{2}{*}{60} & \multirow[t]{2}{*}{130} & \multirow[t]{2}{*}{0.9650} & \multirow[t]{2}{*}{-2.759} & \multirow[t]{2}{*}{ XM_015281453.2 } & \multirow[t]{2}{*}{ this study } \\
\hline & R: CCGTATGGCACTGGGAACAT & & & & & & & & \\
\hline \multirow[t]{2}{*}{ CASP9 } & F: CGGAACCTCAAAGCTCAGGAAA & \multirow[t]{2}{*}{$667 / 668$ (forward primer) } & \multirow[t]{2}{*}{99} & \multirow[t]{2}{*}{60} & \multirow[t]{2}{*}{158} & 0.9524 & -2.425 & XM_424580.6 & this study \\
\hline & R: ATGGGAGAGGATGACCACGA & & & & & & & & \\
\hline PMAIP1 & F: GCCTGCAGAGCGGGAC & 114/115 (forward primer) & 89 & 60 & 130 & 0.9580 & -2.756 & NM_001302097.1 & this study \\
\hline & R: GGTTCAGGACTTTCTGCTGC & & & & & & & & \\
\hline TP53/NP1 & F: ACACTGGCACAACTGGAGG & 813/814 (forward primer) & 72 & 60 & 157 & 0.9520 & -2.429 & XM_015282925.2 & this study \\
\hline & R: GGTAGGAAGAGCTGCGACAA & & & & & & & & \\
\hline TP53/NP2 & F: ATCGAGCTTGGAGAAGAGCC & $527 / 528$ (forward primer) & 96 & 60 & 181 & 0.9418 & -2.227 & XM_015296284.2 & this study \\
\hline & R: GGTGACGTAGACGGACATGC & & & & & & & & \\
\hline$T P 53 B P 2$ & F: CTGTGCAAGGAACCTGGTGA & $326 / 327$ (reverse primer) & 74 & 60 & 152 & 0.9469 & -2.483 & XM_419394.6 & this study \\
\hline & R: TCGGCTATAGGCCGTTCTGA & & & & & & & & \\
\hline CLTA & F: CTAGCAACAGGGTGGCAGAT & 615/616 (reverse primer) & 79 & 60 & 156 & 0.9495 & -2.440 & XM_015280418.2 & this study \\
\hline & R: GCTTCTTCAGCTGCCACATAAC & & & & & & & & \\
\hline$M L K L$ & F: ATTTGAAGGCTGCCCTCTCC & 1216/1217 (forward primer) & 121 & 60 & 206 & 0.9524 & -2.055 & XM_015279230.2 & this study \\
\hline & R: GAAGGCCCGACACTGATTGA & & & & & & & & \\
\hline$T B P^{*}$ & F: CCACGGTGAATCTTGGTTGC & $534 / 535$ (reverse primer) & 88 & 60 & 156 & 0.9423 & -2.447 & NM_205103.1 & 88 \\
\hline & R: GCAGCAAAACGCTTGGGATT & & & & & & & & \\
\hline YWHAZ* & F: TTGCTGCTGGAGATGACAAG & E2/E3 (forward primer) & 61 & 60 & 120 & 0.9656 & -2.910 & NM_001031343.1 & 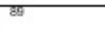 \\
\hline & R: CTTCTTGATACGCCTGTTG & & & & & & & & \\
\hline
\end{tabular}

Table 6. Primer sequence used in qPCR for RNA-Seq data validation. For calculating amplification efficiency, a standard curve was generated using a 10-fold dilution of cDNA. The standard curve was created by plotting the Cq values against the log of the starting quantity of template for each dilution. *Used as reference genes for relative expression data analysis. Exon junction represent the spanning of exon on genes sequence.

\section{Declarations}

\section{Competing Interests:}

The authors declare no competing of interests.

\section{Authors' contributions}

MR.: Developed the hypothesis and designed the experimental work, isolated RNA, constructed cDNA libraries, processed and analysed RNA-seq data, wrote the paper. WYL.: supervised the project, reviewed and edited the paper. MMA.: supervised the project, reviewed and edited the paper. YR.: helped with data 
analysis, reviewed and edited the paper. MIC.: collected samples, reviewed and edited the paper. PTKD.: reviewed and edited paper. ID.: collected samples, reviewed and edited the paper. EDG.: advised on statistical analysis, reviewed and edited the paper. FH.: Acquired funding, supervised the project, reviewed and edited the paper. All authors reviewed and approved the manuscript for publication.

\section{Acknowledgment}

This study was supported by the Australian Centre for International Agricultural Research (project numbers: $A H / 2015 / 003$ and $A H / 2010 / 039)$. The authors appreciate help from Simson Tarigan, and Bbalitvet and Caprifarmindo companies.

\section{References}

1 Miller, P. J. et al. Identification of new sub-genotypes of virulent Newcastle disease virus with potential panzootic features. Infection, genetics and evolution 29, 216-229 (2015).

2 Alexander, D. J., Aldous, E. W. \& Fuller, C. M. The long view: a selective review of 40 years of Newcastle disease research. Avian pathology 41, 329-335 (2012).

3 Miller, P. J., Decanini, E. L. \& Afonso, C. L. Newcastle disease: Evolution of genotypes and the related diagnostic challenges. Infection, Genetics and Evolution 10, 26-35, doi:https://doi.org/10.1016/j.meegid.2009.09.012 (2010).

$4 \quad$ OIE, W. OIE-Listed diseases, infections and infestations in force in 2017. (2016).

5 Doyle, T. A hitherto unrecorded disease of fowls due to a filter-passing virus. Journal of comparative pathology 40, 144-169 (1927).

6 Adi, A. A. A. M., Astawa, N. M., Putra, K. S. A., Hayashi, Y. \& Matsumoto, Y. Isolation and characterization of a pathogenic Newcastle disease virus from a natural case in Indonesia. Journal of Veterinary Medical Science 72, 313-319 (2010).

$7 \quad$ Xiao, S. et al. Generation by reverse genetics of an effective, stable, live-attenuated Newcastle disease virus vaccine based on a currently circulating, highly virulent Indonesian strain. PloS one 7, e52751 (2012).

8 Dimitrov, K. M. et al. Updated unified phylogenetic classification system and revised nomenclature for Newcastle disease virus. Infection, Genetics and Evolution 74, 103917 (2019).

9 Hemmatzadeh, F. Molecular characterisation of newly emerged Newcastle disease viruses in Indonesia. (ACIAR, ACIAR, 2017).

10 Rabiei, M. et al. Genome Sequences of Newly Emerged Newcastle Disease Virus Strains Isolated from Disease Outbreaks in Indonesia. Microbiology Resource Announcements 9 (2020). 
11 Afonso, C. et al. (Edited by OIE. Paris, 2012).

12 Doan, P. T. K. et al. Genome Sequences of Newcastle Disease Virus Strains from Two Outbreaks in Indonesia. Microbiology Resource Announcements 9, e00205-00220, doi:10.1128/mra.00205-20 (2020).

13 Pandarangga, P. et al. Full-Genome Sequences of Two Newcastle Disease Virus Strains Isolated in West Java, Indonesia. Microbiology Resource Announcements 9, e00221-00220, doi:10.1128/mra.00221-20 (2020).

14 Nagai, Y. Virus activation by host proteinases. A pivotal role in the spread of infection, tissue tropism and pathogenicity. Microbiology and immunology 39, 1-9 (1995).

15 Deist, M. S. et al. Resistant and susceptible chicken lines show distinctive responses to Newcastle disease virus infection in the lung transcriptome. BMC genomics 18, 989 (2017).

16 Deist, M. S. et al. Novel mechanisms revealed in the trachea transcriptome of resistant and susceptible chicken lines following infection with Newcastle disease virus. Clin. Vaccine Immunol. 24, e00027-00017 (2017).

17 Deist, M. S. et al. Novel analysis of the Harderian gland transcriptome response to Newcastle disease virus in two inbred chicken lines. Scientific reports 8, 1-9 (2018).

18 Bohnsack, J. \& Brown, E. The role of the spleen in resistance to infection. Annual review of medicine 37, 49-59 (1986).

19 Zhang, J. et al. Transcriptome analysis in spleen reveals differential regulation of response to newcastle disease virus in two chicken lines. Scientific reports 8, 1-13 (2018).

20 Zhang, J. et al. Transcriptome analysis reveals inhibitory effects of lentogenic Newcastle disease virus on cell survival and immune function in spleen of commercial layer chicks. Genes 11, 1003 (2020).

21 Liu, W. et al. Deep sequencing-based transcriptome profiling reveals avian interferon-stimulated genes and provides comprehensive insight into Newcastle disease virus-induced host responses. Viruses 10, 162 (2018).

22 Galluzzi, L. et al. Molecular mechanisms of cell death: recommendations of the Nomenclature Committee on Cell Death 2018. Cell Death \& Differentiation 25, 486-541 (2018).

23 Cuadrado-Castano, S., Sanchez-Aparicio, M. T., García-Sastre, A. \& Villar, E. The therapeutic effect of death: Newcastle disease virus and its antitumor potential. Virus research 209, 56-66 (2015). 
24 Kommers, G., King, D., Seal, B., Carmichael, K. \& Brown, C. Pathogenesis of six pigeon-origin isolates of Newcastle disease virus for domestic chickens. Veterinary Pathology 39, 353-362 (2002).

25 Kalid, M., Jahanshiri, F., Rahman, A. \& Yusoff, K. Gene expression profiling in apoptotic MCF-7 cells infected with newcastle disease virus. Global Vet 5, 334-340 (2010).

26 Ravindra, P. et al. HN protein of Newcastle disease virus causes apoptosis in chicken embryo fibroblast cells. Archives of virology 153, 749-754 (2008).

27 Robbins, S. \& Cotran, R. Cellular adaptations, cell injury and cell death. Pathologic Basis of Disease, V Kumar, AK Abbas, N Fausto, Eds., Saunders-Elsevier, Philadelphia, 26-32 (2009).

28 Brown, C., King, D. \& Seal, B. Pathogenesis of Newcastle disease in chickens experimentally infected with viruses of different virulence. Veterinary pathology 36, 125-132 (1999).

29 Kommers, G. D., King, D. J., Seal, B. S. \& Brown, C. C. Pathogenesis of chicken-passaged Newcastle disease viruses isolated from chickens and wild and exotic birds. Avian diseases 47, 319-329 (2003).

30 Wakamatsu, N., King, D., Kapczynski, D., Seal, B. \& Brown, C. Experimental pathogenesis for chickens, turkeys, and pigeons of exotic Newcastle disease virus from an outbreak in California during 2002-2003. Veterinary Pathology 43, 925-933 (2006).

31 Kommers, G. D., King, D. J., Seal, B. S. \& Brown, C. C. Virulence of pigeon-origin Newcastle disease virus isolates for domestic chickens. Avian diseases, 906-921 (2001).

32 Stolte, M., Haas, L., Wamwayi, H., Barrett, T. \& Wohlsein, P. Induction of apoptotic cellular death in lymphatic tissues of cattle experimentally infected with different strains of rinderpest virus. Journal of comparative pathology 127, 14-21 (2002).

33 Vidalain, P.-O., Azocar, O., Rabourdin-Combe, C. \& Servet-Delprat, C. Measle virus-infected dendritic cells develop immunosuppressive and cytotoxic activities. Immunobiology 204, 629-638 (2001).

$34 \quad$ McCullough, B., Krakowka, S. \& Koestner, A. Experimental canine distemper virus-induced lymphoid depletion. The American journal of pathology 74, 155 (1974).

35 Schobesberger, M., Summerfield, A., Doherr, M. G., Zurbriggen, A. \& Griot, C. Canine distemper virus-induced depletion of uninfected lymphocytes is associated with apoptosis. Veterinary immunology and immunopathology 104, 33-44 (2005).

36 Rodríguez-Ropón, A. et al. Apoptosis in lymph nodes and changes in lymphocyte subpopulations in peripheral blood of pigs infected with porcine rubulavirus. Journal of comparative pathology 128, 1-8 (2003). 
37 Waldron, C. \& Lacroute, F. Effect of growth rate on the amounts of ribosomal and transfer ribonucleic acids in yeast. Journal of bacteriology 122, 855-865 (1975).

38 Van Herreweghe, F., Festjens, N., Declercq, W. \& Vandenabeele, P. Tumor necrosis factor-mediated cell death: to break or to burst, that's the question. Cellular and Molecular Life Sciences 67, 1567-1579 (2010).

39 Rue, C. A. et al. Virulent Newcastle disease virus elicits a strong innate immune response in chickens. Journal of general virology 92, 931-939 (2011).

40 Lan, D., Tang, C., Li, M. \& Yue, H. Screening and identification of differentially expressed genes from chickens infected with Newcastle disease virus by suppression subtractive hybridization. Avian pathology 39, 151-159 (2010).

41 Saelao, P. et al. Novel insights into the host immune response of chicken Harderian gland tissue during Newcastle disease virus infection and heat treatment. BMC veterinary research 14, 1-11 (2018).

42 Schilling, M. A. et al. Transcriptional innate immune response of the developing chicken embryo to Newcastle disease virus infection. Frontiers in genetics 9, 61 (2018).

43 Sun, Y. et al. Autophagy benefits the replication of Newcastle disease virus in chicken cells and tissues. Journal of virology 88, 525-537 (2014).

44 Zhang, S. et al. Activation of the PKR/elF2a signaling cascade inhibits replication of Newcastle disease virus. Virology journal 11, 1-11 (2014).

45 Krämer, A., Green, J., Pollard Jr, J. \& Tugendreich, S. Causal analysis approaches in ingenuity pathway analysis. Bioinformatics 30, 523-530 (2014).

46 Schroder, K., Hertzog, P. J., Ravasi, T. \& Hume, D. A. Interferon- $\gamma$ : an overview of signals, mechanisms and functions. Journal of leukocyte biology 75, 163-189 (2004).

47 Sachan, S. et al. Adjuvant potential of resiquimod with inactivated Newcastle disease vaccine and its mechanism of action in chicken. Vaccine 33, 4526-4532 (2015).

48 Deist, M. S. et al. Novel mechanisms revealed in the trachea transcriptome of resistant and susceptible chicken lines following infection with Newcastle disease virus. Clinical and Vaccine Immunology 24, e00027-00017 (2017).

49 Araki, K. et al. mTOR regulates memory CD8 T-cell differentiation. Nature 460, 108-112 (2009).

50 Ma, J., Sun, Q., Mi, R. \& Zhang, H. Avian influenza A virus H5N1 causes autophagy-mediated cell death through suppression of mTOR signaling. Journal of Genetics and Genomics 38, 533-537 (2011). 
51 Shrivastava, S., Chowdhury, J. B., Steele, R., Ray, R. \& Ray, R. B. Hepatitis C virus upregulates Beclin 1 for induction of autophagy and activates mTOR signaling. Journal of virology $86,8705-8712$ (2012).

52 Shrestha, N. et al. Eukaryotic initiation factor 2 (elF2) signaling regulates proinflammatory cytokine expression and bacterial invasion. Journal of Biological Chemistry 287, 28738-28744 (2012).

53 Zeilhofer, H. U. \& Schorr, W. Role of interleukin-8 in neutrophil signaling. Current opinion in hematology 7, 178-182 (2000).

54 Verbist, K. C. \& Klonowski, K. D. Functions of IL-15 in anti-viral immunity: multiplicity and variety. Cytokine 59, 467-478 (2012).

55 Fowell, D. J. et al. Impaired NFATc translocation and failure of Th2 development in Itk-deficient CD4+ T cells. Immunity 11, 399-409 (1999).

56 Broussard, C. et al. Altered development of CD8+ T cell lineages in mice deficient for the Tec kinases Itk and RIk. Immunity 25, 93-104 (2006).

57 Stepaniak, J. A., Shuster, J. E., Hu, W. \& Sundick, R. S. Production and in vitro characterization of recombinant chicken interleukin-2. Journal of interferon \& cytokine research 19, 515-526 (1999).

58 Staeheli, P., Puehler, F., Schneider, K., Göbel, T. W. \& Kaspers, B. Cytokines of birds: conserved functions-a largely different look. Journal of interferon \& cytokine research 21, 993-1010 (2001).

59 Yu, P. et al. Specific T regulatory cells display broad suppressive functions against experimental allergic encephalomyelitis upon activation with cognate antigen. Journal of immunology (Baltimore, Md. : 1950) 174, 6772-6780, doi:10.4049/jimmunol.174.11.6772 (2005).

60 Descatoire, M. et al. Identification of a human splenic marginal zone B cell precursor with NOTCH2-dependent differentiation properties. The Journal of experimental medicine 211, 987-1000, doi:10.1084/jem.20132203 (2014).

61 Deist, M. S., Gallardo, R. A., Dekkers, J., Zhou, H. \& Lamont, S. J. Novel combined tissue transcriptome analysis after lentogenic Newcastle disease virus challenge in inbred chicken lines of differential resistance. Frontiers in Genetics 11, 11 (2020).

62 Schilling, M. A. et al. Innate immune genes associated with newcastle disease virus load in chick embryos from inbred and outbred lines. Frontiers in microbiology 10, 1432 (2019).

63 Gower, T. L. et al. RhoA signaling is required for respiratory syncytial virus-induced syncytium formation and filamentous virion morphology. Journal of virology 79, 5326-5336 (2005). 
64 Martínez, A. et al. TrkB and TrkC signaling are required for maturation and synaptogenesis of hippocampal connections. Journal of Neuroscience 18, 7336-7350 (1998).

65 Zhang, B., Liu, X., Chen, W. \& Chen, L. IFIT5 potentiates anti-viral response through enhancing innate immune signaling pathways. Acta Biochim Biophys Sin 45, 867-874 (2013).

66 Abbas, Y. M., Pichlmair, A., Górna, M. W., Superti-Furga, G. \& Nagar, B. Structural basis for viral 5'PPP-RNA recognition by human IFIT proteins. Nature 494, 60-64 (2013).

67 Zheng, C. et al. IFIT5 positively regulates NF-KB signaling through synergizing the recruitment of IKB kinase (IKK) to TGF- $\beta$-activated kinase 1 (TAK1). Cellular signalling 27, 2343-2354 (2015).

68 Rohaim, M. A. et al. Chickens Expressing IFIT5 ameliorate clinical outcome and pathology of highly pathogenic avian influenza and velogenic newcastle disease viruses. Frontiers in Immunology $\mathbf{9}$, 2025 (2018).

69 Suarez, D. L., Miller, P. J., Koch, G., Mundt, E. \& Rautenschlein, S. Newcastle disease, other avian paramyxoviruses, and avian metapneumovirus infections. Diseases of poultry, 109-166 (2020).

70 Miller, P. J. et al. Effects of Newcastle disease virus vaccine antibodies on the shedding and transmission of challenge viruses. Developmental \& Comparative Immunology 41, 505-513 (2013).

71 Alexander, D. J., Manvell, R. J. \& Parsons, G. Newcastle disease virus (strain Herts 33/56) in tissues and organs of chickens infected experimentally. Avian Pathology 35, 99-101 (2006).

72 Shirima, R. R. et al. Absolute quantification of cassava brown streak virus mRNA by real-time qPCR. Journal of Virological Methods 245, 5-13, doi:https://doi.org/10.1016/j.jviromet.2017.03.003 (2017).

73 Andrews, S. Babraham bioinformatics-FastQC a quality control tool for high throughput sequence data. URL: https://www. bioinformatics. babraham. ac. uk/projects/fastqc/(accessed 06.12. 2018) (2010).

$74 \quad$ Krueger, F. Trim galore. A wrapper tool around Cutadapt and FastQC to consistently apply quality and adapter trimming to FastQ files 516, 517 (2015).

75 Schubert, M., Lindgreen, S. \& Orlando, L. AdapterRemoval v2: rapid adapter trimming, identification, and read merging. BMC research notes $\mathbf{9}, 88$ (2016).

76 Kim, D., Langmead, B. \& Salzberg, S. L. HISAT: a fast spliced aligner with low memory requirements. Nature methods 12, 357-360 (2015).

$77 \mathrm{Li}, \mathrm{H}$. et al. The sequence alignment/map format and SAMtools. Bioinformatics 25, 2078-2079 (2009). 
78 Liao, Y., Smyth, G. K. \& Shi, W. featureCounts: an efficient general purpose program for assigning sequence reads to genomic features. Bioinformatics 30, 923-930 (2014).

79 Ritchie, M. E. et al. limma powers differential expression analyses for RNA-sequencing and microarray studies. Nucleic acids research 43, e47-e47 (2015).

80 Liu, R. et al. Why weight? Modelling sample and observational level variability improves power in RNA-seq analyses. Nucleic acids research 43, e97-e97 (2015).

81 Robinson, M. D. \& Oshlack, A. A scaling normalization method for differential expression analysis of RNA-seq data. Genome biology 11, R25 (2010).

82 Dwight, Z., Palais, R. \& Wittwer, C. T. uMELT: prediction of high-resolution melting curves and dynamic melting profiles of PCR products in a rich web application. Bioinformatics 27, 1019-1020 (2011).

83 Hellemans, J., Mortier, G., De Paepe, A., Speleman, F. \& Vandesompele, J. qBase relative quantification framework and software for management and automated analysis of real-time quantitative PCR data. Genome biology 8, 1-14 (2007).

84 Pfaffl, M. W. \& Hageleit, M. Validities of mRNA quantification using recombinant RNA and recombinant DNA external calibration curves in real-time RT-PCR. Biotechnology Letters 23, 275-282 (2001).

85 Laboratories, B.-R. 2-6 (Bio-Rad Laboratories Hercules, CA, 2006).

86 Rasmussen, R. (Springer Press: Berlin, 2001).

87 Khan, S., Roberts, J. \& Wu, S.-B. Reference gene selection for gene expression study in shell gland and spleen of laying hens challenged with infectious bronchitis virus. Scientific reports 7, 1-12 (2017).

88 Khan, S. \& Chousalkar, K. K. Transcriptome profiling analysis of caeca in chicks challenged with Salmonella Typhimurium reveals differential expression of genes involved in host mucosal immune response. Applied Microbiology and Biotechnology, 1-16 (2020).

89 Bagés, S., Estany, J., Tor, M. \& Pena, R. Investigating reference genes for quantitative real-time PCR analysis across four chicken tissues. Gene 561, 82-87 (2015).

\section{Figures}


FDR: $0.05, \log 2 \mathrm{FC}: 1.0$, upregulated: 3506 , downregulated: 2855

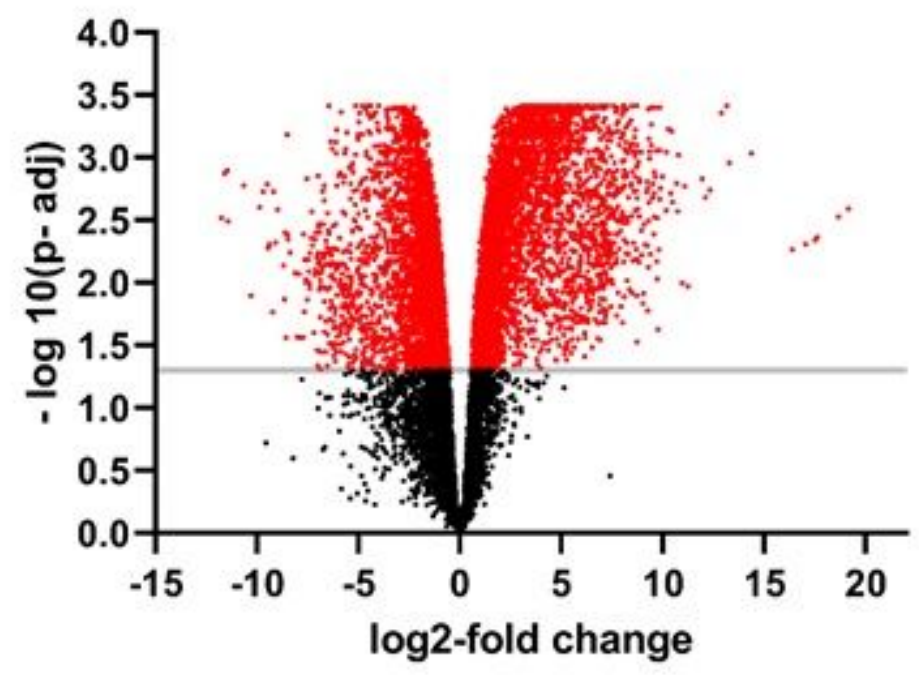

Figure 1

The volcano plot of differentially expressed genes between challenged and control birds. Red dots indicate significantly up-regulated $(p<0.05, \log 2$ fold change $\geq 1)$ and down-regulated genes $(p<0.05$, log2 fold change $\leq-1)$. Black dots represent genes that were not differentially expressed.

$$
\mathrm{R}=0.98
$$

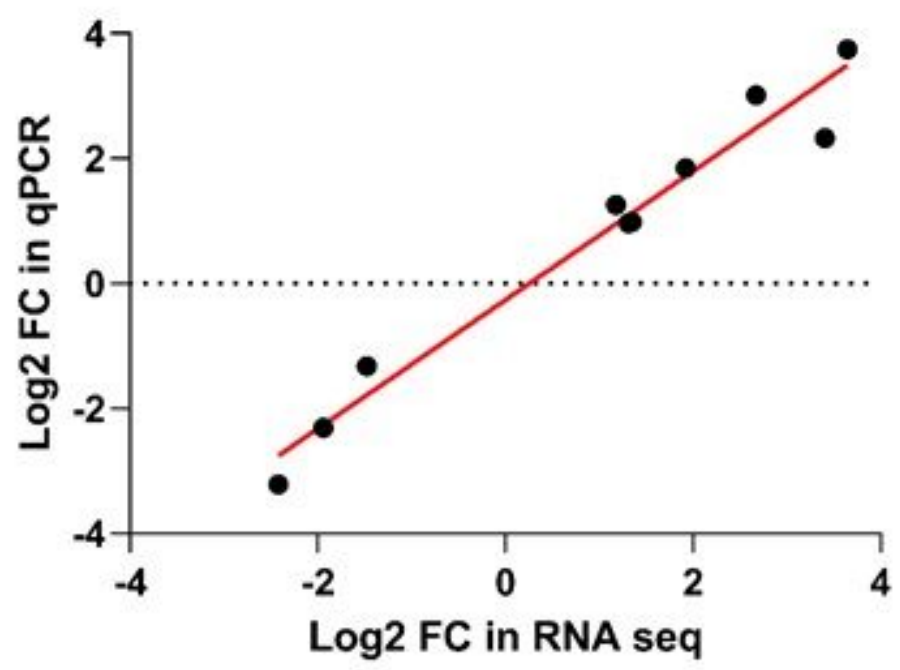

Figure 2

Validation of RNA-Seq data using ABI Quant studio qPCR system. The mean expression of 10 selected genes was calculated by $-\triangle \triangle C T$ method and normalised by mean of $C t$ values of YWHAZ and TBP YWHAZ as reference genes. The values were converted into log2 fold change (LFC). Each dot point represents one gene. Pearson correlation coefficient test used to compare the results and its value labelled as "R". Plus (+) and minus (-) signs indicate log2 FC values for the upregulated and downregulated genes, respectively. 


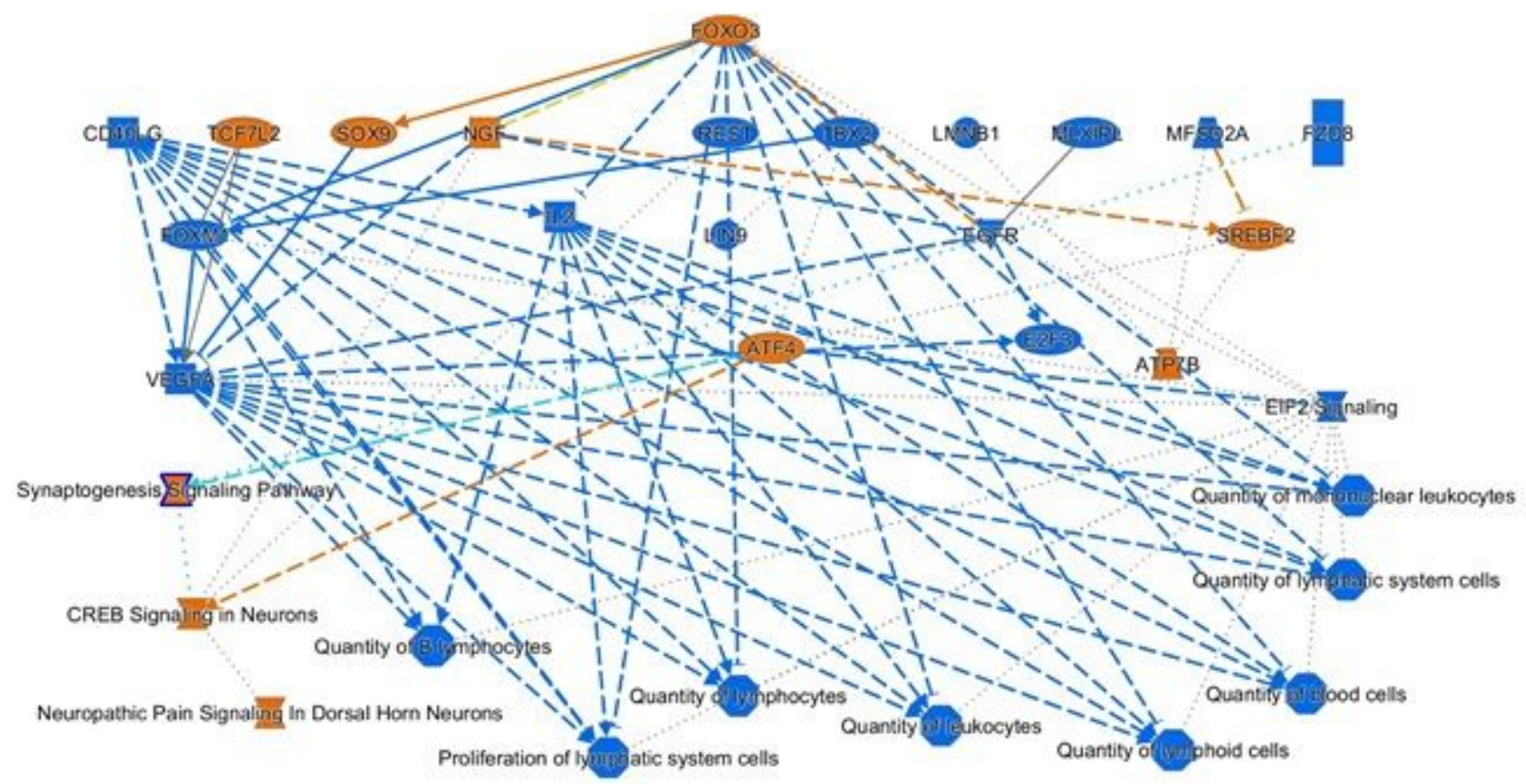

Figure 3

Major biological themes (pathways, upstream regulators, disease and biological functions) obtained from mapping the significantly upregulated DEGs in the spleen of chicks post infection. In IPA, only significantly enriched entities that passed a Fisher's exact test p-value cut of 0.05 and also passes an absolute z-score cut-off of 2 or greater were visualised. Orange nodes are predicted to be activated (zscore $\geq 2$ ), while blue nodes are predicted to be inhibited ( $z$-score $\geq 2$ ). Blue line: leads to inhibition, orange line: leads to activation green lines: decreased measurement.

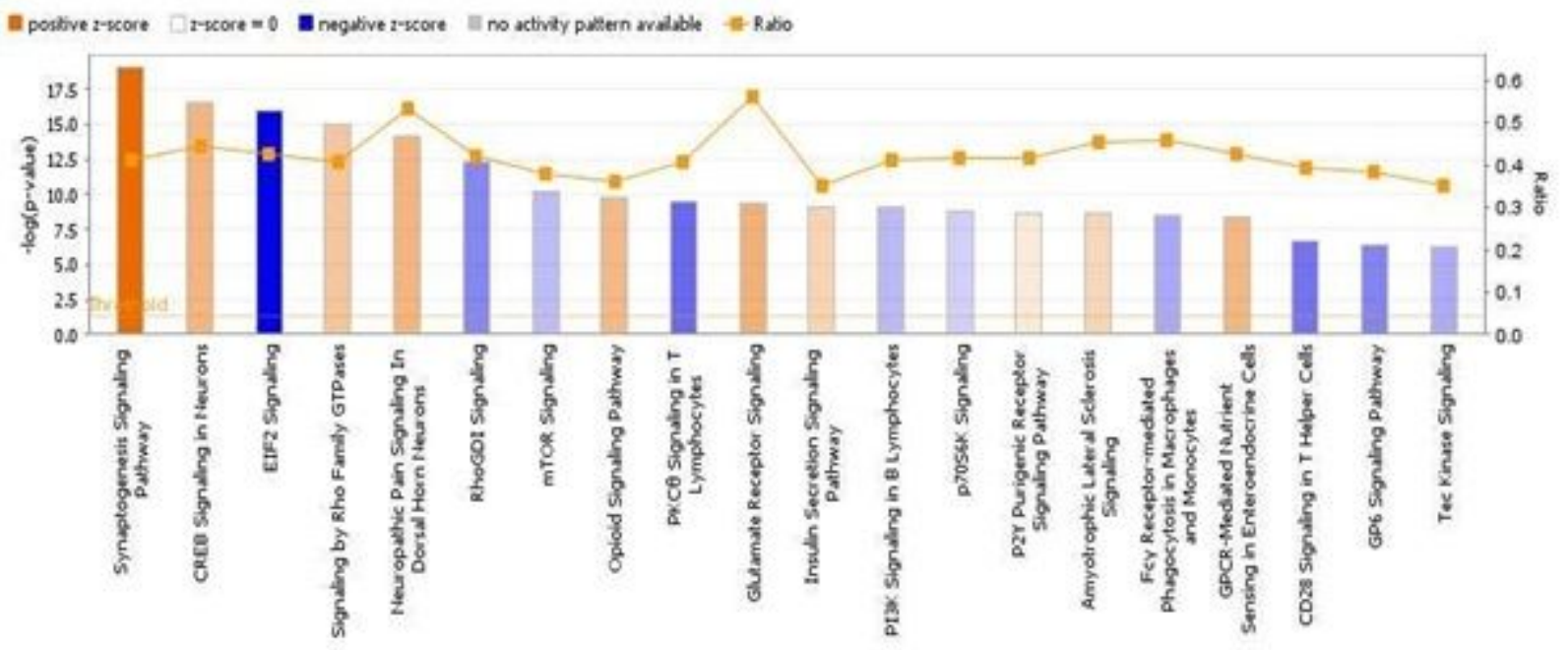

Figure 4

Top pathways of differentially expressed genes (FDR $<0.05$ ). Pathways [Z-score $>0.05$, - log ( $p$ value) $>1.3]$ in orange predicted to be activated and pathways in blue predicted to be inhibited. The more 
intensity of the colours, the higher absolute z-score. The proportion of genes within the pathways that were differentially expressed are indicated by the orange line as ratios. The height of each bar refers to the-log (p-value).

\section{Supplementary Files}

This is a list of supplementary files associated with this preprint. Click to download.

- SupplementaryTablesS13.xlsx 